\title{
Preparation Poly(lactide-co-glycolide) Microsphere of Bone Sialoprotein
}

\author{
Xinmei Liao, Jie Wang*, Jiangtao Wang, Hongbin Zhang \\ Department of medical research, Guangzhou general hospital of guanghzou military area, Guangdong Guangzhou 510010, China \\ *Corresponding authors. Email: jiew@tom.com
}

\begin{abstract}
OBJECTIVE: To prepare PLGA microsphere of BSP. METHODS: mulsion solvent extraction-evaporation process was used to prepare microsphere. Technology of preparation was optimized by the orthogonal design. The surface morphology of the microsphere was observed by EM and SEM. The drug loading, the encapsulation efficiency and release rate in vitro were measured using microBCA kit. RESULTS: The mean particle size of the microsphere was $50 \pm 0.5 \mu \mathrm{m}$, and its mean span was $0.58 \pm 0.10$, the drug loading and the encapsulation efficiency were $(0.725 \pm 0.075) \%$ and $(64.876 \pm 0.680) \%$ respectively. The reappearance of pharmaceutical technology was good. CONCLUSION: this research described the optimized preparation technology of PLGA microspheres of BSP.
\end{abstract}

Keywords: Bone sialoprotein; Poly(lactide-co-glycolide); Orthogonal design

Citation: X. Liao et al. Preparation Poly(lactide-co-glycolide) Microsphere of Bone Sialoprotein. Nano Biomed Eng. 2010, 2(2), 133-137. DOI: 10.5101/nbe.v2i2.p133-137.

\section{Introduction}

Bone sialoprotein(BSP for short) is a non-collagen protein of glycosylation, phosphorylation and sulfation mainly secreted by osteoblasts and osteoclasts, which was extracted from cattle bone for the first time in 1972, belongs to proteins family of SIBLING(small integrinbinding ligand, N-linked glycoproteins) [1]. BSP is rich in sialic acid(named $\mathrm{N}$-acetyl neuraminidase of the end of sugar chain) which is an acyl derivative of neuraminidase [13]. Molecular weight of BSP is $70 \sim 80 \mathrm{kD}$, core protein is $33 \sim 34 \mathrm{kD}$.

Since BSP can start mineralization crystal growth when bone comes into being, it also mediates the combination between osteoblasts and bone mineral as well as having effects of inducing bone differentiation and remodeling bone shape. However, BSP is applied systemically or locally, effective concentration in position of bone defect can not be maintained, it affects bone recovering, and therefore consider preparing slowrelease microspheres of BSP to release BSP stably in vivo and promote bone repair. PLGA(lactide-coglycolide) is a polymer copolymer which is polymerized by lactide(LA) and glycolic acid(GA) under the catalyst, PLGA has been approved by the U.S. FDA for carrier of slow-release drug. Slow-release microspheres of BSP has not been reported at home and abroad.

This research is reported as follow: optimized technique parameters and prepared the PLGA slow-release microspheres of BSP which can sustainedly release BSP.

\section{Materials and instruments}

BSP [2], purity $>95 \%$; PLGA, LA:GA $=50 / 50$, Chengdu Organic Chemistry Co.Ltd.,Chinese Academy of Sciences; methylene chloride, analytical grade, Guangzhou Xincheng Fine Chemical Plant; polyvinyl alcohol, analytical grade, Tianjin Kermel Chemical Reagent Co.,Ltd.; Micro BCA Protein Assay Kit, Pierce Company; Kubota 5220 centrifuge, Kubota Corporation, Japan; nikon E600, Nikon Corporation, Japan; Hitachi S-3000N scanning electron microscope, Hitachi, Japan; sigma1-15 centrifuge, Sigma, Germany; Biocell ht2 Reader, Biocell Company, Australia; JY92 -2D ultrasonic cell crusher, Ningbo Xinzhi Biology and Science Co.,Ltd.; 85-2 type homoiothermous and magnetic stirrer, Jiangsu Ronghua Instrument Manufacturing Co.,Ltd.; LGJ-12 vacuum freeze dryer, Beijing Songyuan Huaxing Science and Technology Development Co.,Ltd. 
Table 1 Factor-level in orthogonal design

\begin{tabular}{|c|c|c|c|c|}
\hline \multirow[b]{2}{*}{ level } & \multicolumn{4}{|c|}{ factors } \\
\hline & A & B & $\mathrm{C}$ & D \\
\hline & concentration & volume ratio of intemal & concentration & ultrasonic power \\
\hline & of PLGA & and external phase & of PVA & \\
\hline & $A \%(w / v)$ & $(\mathrm{v} / \mathrm{v})$ & $A \%(w / v)$ & (W) \\
\hline 1 & $6 \%$ & $1: 8$ & $2 \%$ & 200 \\
\hline 2 & $9 \%$ & $1: 12$ & $4 \%$ & 300 \\
\hline 3 & $12 \%$ & $1: 16$ & $6 \%$ & 500 \\
\hline
\end{tabular}

Drug loading, encapsulation efficiency and span were different under different experimental condition(Table 2).

Table 2 Results of orthogonal experiment $(\bar{x} \pm \mathrm{S}, \mathrm{n}=3)$

\begin{tabular}{cccccccc}
\hline $\begin{array}{c}\text { Number of } \\
\text { experiments }\end{array}$ & A & B & C & D & $\begin{array}{c}\text { encapsulation } \\
\text { efficiency }(\%)\end{array}$ & drug 1oading(\%) & span \\
\hline 1 & 1 & 1 & 1 & 1 & $25.20 \pm 0.60$ & $0.552 \pm 0.002$ & $0.75 \pm 0.015$ \\
2 & 2 & 2 & 2 & 2 & $34.64 \pm 0.80$ & $0.596 \pm 0.018$ & $0.65 \pm 0.010$ \\
3 & 1 & 3 & 3 & 3 & $36.00 \pm 1.00$ & $0.564 \pm 0.009$ & $1.15 \pm 0.030$ \\
4 & 2 & 1 & 2 & 3 & $34.00 \pm 0.90$ & $0.650 \pm 0.025$ & $0.80 \pm 0.008$ \\
5 & 2 & 2 & 3 & 1 & $51.31 \pm 1.30$ & $0.644 \pm \pm 0.015$ & $1.25 \pm 0.020$ \\
6 & 2 & 3 & 1 & 2 & $45.00 \pm 1.25$ & $0.624 \pm 0.024$ & $1.00 \pm 0.011$ \\
7 & 3 & 1 & 3 & 2 & $73.33 \pm 1.66$ & $0.750 \pm 0.040$ & $1.31 \pm 0.013$ \\
8 & 3 & 2 & 1 & 3 & $54.24 \pm 1.48$ & $0.618 \pm 0.018$ & $0.83 \pm 0.005$ \\
9 & 3 & 3 & 2 & 1 & $63.46 \pm 2.30$ & $0.736 \pm 0.036$ & $0.53 \pm 0.008$ \\
& & & & & & &
\end{tabular}

\subsection{Preparing microspheres with double emulsion evaporation}

Prepared microspheres by double emulsion solvent evaporation method using a model protein such as BSA [3]: moderate PLGA was dissolved in dichloromethane and then appropriate BSA solution was taken to disperse in it to form colostrum under ultrasound, the colostrum was added slowly into the PVA solution to form a double emulsion which was mixed continuously to volatilize organic solvents, then the microspheres were centrifuged for $6 \mathrm{~min}$ at $1500 \mathrm{rpm}$ and washed with distilled water, finally, they were freeze-dried and preserved at $-20{ }^{\circ} \mathrm{C}$. Optimized process parameters of PLGA microspheres of BSP using orthogonal design were shown in 3.1 results.

\subsection{Microsphere morphology, particle size and dis- tribution}

Microspheres morphology was observed using optical microscope and scanning electron microscopy. Particle size and span were detected by microscopic counting microsphere at least 200 for each count. Span was calculated as follows: span=(D90-D10)/D50, D90, D10, D50 is particle size when particle size of $90 \%, 10 \%$, $50 \%$ microspheres is less than the value respectively [4].

\subsection{Measuring BSP concentration in microspheres}

\subsubsection{Establishing the standard curve}

Using micro-BCA method [5], the operational steps according to the kit instructions: (1), prepared accurately standard solutions of different protein concentration: $0.0 \mu \mathrm{g} / \mathrm{ml}, 0.50 \mu \mathrm{g} / \mathrm{ml}, 1.0 \mu \mathrm{g} / \mathrm{ml}, 2.5 \mu \mathrm{g} / \mathrm{ml}, 5.0 \mu \mathrm{g} / \mathrm{ml}$, $10.0 \mu \mathrm{g} / \mathrm{ml}, 20.0 \mu \mathrm{g} / \mathrm{ml}, 40.0 \mu \mathrm{g} / \mathrm{ml}$. (2), prepared working solution, A solution:B solution:C solution=50:48:2. (3), standard solution of different concentration was added to microtiter plate per hole $150 \mu \mathrm{l}$, each concentration repeated twice, and then added 150 $\mu \mathrm{l}$ working fluid to each well, shaking a little so as to mix well. (4), incubated for $2 \mathrm{~h}$ at $37{ }^{\circ} \mathrm{C}$. (5), the microtiter plate was then cooled to room temperature and read OD values at $562 \mathrm{~nm}$. (6), maked the measured data correspond to the standard concentration and used linear regression analysis, the regression equation was $\mathrm{A}=0.006+0.009 \mathrm{x} * \mathrm{c}(\mu \mathrm{g} / \mathrm{ml})$, the correlation coefficient $\mathrm{r}=0.997$, linear relationship was good.

Table 3 Results analysis of orthogonal design

\begin{tabular}{|c|c|c|c|c|c|c|c|c|c|c|c|c|}
\hline & \multicolumn{4}{|c|}{ encapsulation efficiency } & \multicolumn{4}{|c|}{ drug loading } & \multicolumn{4}{|c|}{ span } \\
\hline & $\bar{A}$ & B & $\mathrm{C}$ & D & A & B & C & $\bar{D}$ & A & B & $\mathrm{C}$ & $\bar{D}$ \\
\hline $\mathrm{K}_{1}$ & 31.947 & 44.177 & 41.480 & 46.657 & 0.571 & 0.651 & 0.5980 & 0.644 & 0.883 & 30.987 & 770.860 & 0.860 \\
\hline $\mathrm{K}_{2}$ & 43.437 & 46.730 & 44.033 & 50.990 & 0.639 & 0.619 & 0.6610 & 0.657 & 1.033 & 30.927 & 70.660 & 1.020 \\
\hline $\mathrm{K}_{3}$ & 63.677 & 48.153 & 53.547 & 41.413 & 0.701 & 0.641 & 0.6530 & 0.611 & 0.923 & 30.927 & 271.320 & 0.960 \\
\hline $\mathrm{R}$ & 31.730 & 3.976 & 12.067 & 9.577 & 0.130 & 0.032 & 0.0630 & 0.046 & 0.150 & 00.060 & 500.660 & 0.160 \\
\hline P & * & & & & & & & & & & * & \\
\hline
\end{tabular}

2.3.2 Measuring BSP concentration in microspheres

Weighed $10 \mathrm{mg}$ dried microspheres which then were dissolved in $4 \mathrm{ml} 0.1 \mathrm{~mol} / \mathrm{L} \mathrm{NaOH}$ solution (containing $5 \%$ SDS), shacking for $24 \mathrm{~h}$ at $37{ }^{\circ} \mathrm{C}$, centrifuged to obtain supernatant and read OD values with microBCA method which were substituted in an equation of standard curve to calculate the concentration of protein: microsphere drug loading $=$ (weight of BSP in microspheres/weight of microspheres $\times 100 \%$;

encapsulation efficiency $=$ (weight of BSP in microspheres/inventory rating $) \times 100 \%$.

\subsection{Releasing test of BSP microspheres in vitro}

Weighed $10 \mathrm{mg}$ microspheres and put in $15 \mathrm{ml}$ centrifuge tubes, $0.02 \mathrm{~mol} / \mathrm{L}$ PBS buffer(pH7.4, $0.02 \%$ $\mathrm{NaN}_{3}$ ) of $4 \mathrm{ml}$ was added into, shoke at $50 \mathrm{rpm}, 37{ }^{\circ} \mathrm{C}$, centrifuge tube was centrifuged for $5 \mathrm{~min}$ at $2100 \mathrm{rpm}$ on $1 \mathrm{~d}, 3 \mathrm{~d}, 7 \mathrm{~d}, 12 \mathrm{~d}, 17 \mathrm{~d}, 21 \mathrm{~d}, 25 \mathrm{~d}, 30 \mathrm{~d}$, obtained supernatant $0.8 \mathrm{ml}$ (added to the centrifuge tube $0.8 \mathrm{ml}$ PBS buffer at the same time ) which was then centrifuged for $1 \mathrm{~min}$ at $12000 \mathrm{rpm}$, took $0.6 \mathrm{ml}$ to measure with micro BCA method. The release time was horizontal and the percentage of cumulative release was vertical axis, drew a chart. Percentage of cumulative release $=$ (total protein releasing from microspheres/total protein in microspheres) $\times 100 \%$. Repeated testing percentage of cumulative release three times, said data was shown as $\bar{x}_{ \pm} \mathrm{SEM}$.

\section{Results}

\subsection{Orthogonal experiment and analysis}

3.1.1 Single factor of preparation PLGA microspheres of BSP 
Different single factor was considered to effect onquality of microspheres: selected PLGA concentration range from $3 \%$ to $15 \%$, internal and external phase volume ratio 1:6 1:18, PVA concentration $0.5 \% \sim 8 \%$, ultrasonic power and time $100 \mathrm{~W} \sim 500 \mathrm{~W}, 30 \mathrm{~s} \sim 120 \mathrm{~s}$, stirring speed $800 \mathrm{rpm} \sim 2400 \mathrm{rpm}$, the ratio of inventory rating was $1: 2$ to $1: 8$ and so on. Make sure other factors were constant so as to investigate the influence of single factor on encapsulation efficiency and drug loading.
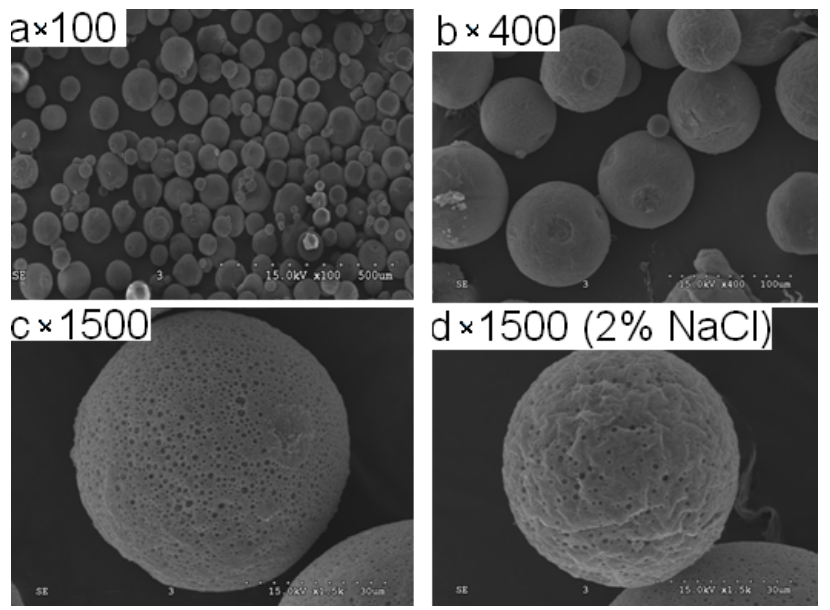

Figure 1. Scanning electron microscope of PLGA microspheres of BSP

The encapsulation efficiency and drug loading of microspheres increased as concentration of PLGA increased from $3 \%$ to $12 \%$, from $12 \%$ to $15 \%$, the encapsulation efficiency increased unconspicuously, but drug loading decreased. Therefore, this experiment used $6 \%$ to $12 \%$ concentration of PLGA. When internal and external phase volume ratio is $1: 18$, output rate of microspheres was low relatively; $1: 6$, the reaction system was so viscous not to diffuse microspheres equably. For this reason, we confirmed that the internal and external phase volume ratio was 1:8 1:16. Low ultrasonic power and short ultrasonic time resulted in incomplete emulsification of colostrum, contrariwise, it led to protein inactivation easily, finally the power range was $200 \mathrm{~W} 3300 \mathrm{~W}$, ultrasonic time was $30 \mathrm{~s}$. When stirring rate was low, no regular microspheres formed, having severe adhesion each other, the higher the stirring rate, the smaller particle size of microspheres. Because of utility of microspheres in this research is for tissue embedding not for injection, having no strict requirements on the size, consequently, stirring rate was $1500 \mathrm{rpm}$ for $10 \mathrm{~min}$ when the colostrum was put into the external phase, and then adjusted to $1000 \mathrm{rpm}$ to volatilize organic solvents. Microspheres dispersed well at low concentration of PVA, but it was so low to burst release seriously while so high to form a block easily in the mixing process. Determined the concentration of PVA was $2 \% \sim 6 \%$. With increasing feed ratio, the encapsulation efficiency and the drug loading of microspheres increased gradually, but when it increased to $1: 2$, the encapsulation efficiency and drug loading did not increase, indicating drug loading capacity of microspheres was limited, range from 1:4 to $1: 8$ was selected.

\subsubsection{Design and analysis of orthogonal experiment}

Selected four factors which effected the quality of microspheres more significantly: concentration of PLGA in the organic phase, volume ratio of internal and external phase(solution volume ratio of PLGA and PVA), concentration of PVA, ultrasonic power(table 1). Optimized process conditions according to L9 $\left(3^{4}\right)$ orthogonal design, repeated three times each level, drug loading, encapsulation efficiency and span (evenness) were assessment criteria.

The results of the orthogonal design were for visual analysis and variance analysis, the $\mathrm{R}$ value from table 3 can be judged, PLGA concentration had a great impact on drug loading and encapsulation efficiency, effect of PVA concentration on span was obvious. The larger the $\mathrm{K}$ value, the smaller the level of span, the better drug loading and encapsulation efficiency of microspheres. Variance analysis of the data in table 2 suggested that the influence of the concentration of PLGA on encapsulation efficiency of BSP microspheres were significantly different $(\mathrm{P}<0.05)$, while the influence of volume ratio of internal and external phase, PVA concentration and ultrasonic power on the drug loading and encapsulation efficiency had not significant difference $(\mathrm{P}>0.05)$; PVA concentration on particle size and span of microspheres had significant influence $(\mathrm{P}<0.05)$.

The best experimental combination was A3-B3-C2D2, the PLGA concentration of $120 \mathrm{mg} / \mathrm{ml}$, internal and external phase volume ratio of 1:16, PVA concentration in the dispersed phase of $4 \%$, ultrasonic power is $300 \mathrm{~W}$. Repeated preparation of the 3 batches of BSP microspheres, average diameter was $50 \pm 0.5 \mu \mathrm{m}$, the average span was $0.58 \pm 0.10$, the average drug loading was $(0.725 \pm 0.075) \%$, the average encapsulation efficiency was $(64.876 \pm 0.680) \%$, optimized condition of preparing microsphere had good reproducibility withing the multiple emulsion solvent evaporation method.

\subsection{Microsphere morphology and particle size}

Shown in figure 1, BSP microspheres were observed under scanning electron microscope with different magnification multiple, they were round, uniformly dense surface porosity, average particle size was $50 \mu \mathrm{m}$ almost, diameter of more than $90 \%$ microspheres was between $40 \mu \mathrm{m}$ and $70 \mu \mathrm{m}$. Added $2 \% \mathrm{NaCl}$ aqueous solution into external phase when prepared BSP microspheres and found that the number of surface void on microspheres decrease and aperture became smaller, it suggested that adding $\mathrm{NaCl}$ to the external phase can 
mitigate microsphere burst and make microsphere release relatively flat.

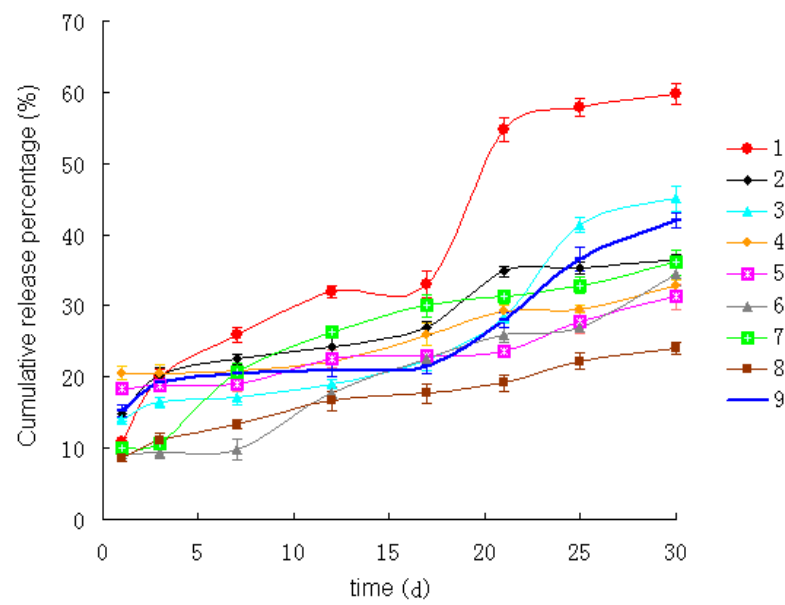

Figure 2. Cumulative release in vitro of BSP from PLGA microspheres

\subsection{Results of microspheres release in vitro}

The results of nine groups microspheres in vitro release for 30 days with orthogonal design were shown in Figure 2. There was certain different release behavior of microspheres under different preparation conditon, good release curve should have relatively low burst release within $24 \mathrm{~h}$, the whole process of release was flat, such as the 9th group release curve. Difference of preparation process between the 9th group microspheres and the optimal microspheres was only ultrasonic power, both of their release curves were very similar.

\section{Discussion}

We have done experiments using PLGA of different proportions (LA/GA, 50/50, 75/25) before, their viscosity and molecular weight were different, so were degradation rate in vitro, because the viscosity of 75/25 was higher than 50/50', preparation PLGA microspheres at a lower concentration of 75/25 can achieve, but the time of degradation was up to three months. From the application point of view, experiments in this research used the former (50/50). On the other hand, microsphere suspension needed to be precooled at $4{ }^{\circ} \mathrm{C}$, $-20{ }^{\circ} \mathrm{C}$ for $2 \sim 4 \mathrm{~h}$ respectively before freeze-drying for taking into account the integrity of microspheres.

The concentration of PLGA microsphere had great influence on drug loading and encapsulation efficiency, in a certain range, the encapsulation efficiency and drug loading will increased as the concentration increased, but the concentrations increase can not be unlimited, encapsulation efficiency didn't increase any more when PLGA concentration reached to a high level, while the drug loading was slow to decline and they cost more. PVA concentration and volume ratio of internal and external phase had influence on microsphere size and span, generally, increasing concentration of PVA resulted in minishing the microsphere size, the smaller the volume ratio of internal and external phase, the better the microspheres dispersed, the shorter the span. Ultrasonic power was too low to emulsify completely and so high to make a great impact on protein and affect its activity. While ultrasonic time should be as short as possible to avoid adverse impact on protein activity between water interface and oil interface.

There were two factors affecting the release of protein drugs, one was correlative with the surface morphology of microspheres, LA/GA ratio and molecular weight (viscosity) of the polymer, large holes on the surface of microsphere and small size, burst release seriously [6]; the other was drug the structural characteristics itself and molecular weight. Release of BSP protein is incomplete in figure 2, that may result of interaction between protein with polymer microspheres [7].

In this research, we prepared the PLGA microspheres of BSP, optimized process and obtained good results using orthogonal design. The next step is to measure the activity of BSP in the microspheres so as to confirm whether BSP activity will be affected by the process of preparation and in vitro release, on the other hand, we should promote research of integration between osteoblast and bone mineral for creating the conditions in clinical application of BSP.

\section{Acknowledgements}

This research was supported by Key Projects in Guangdong Province Natural Science Foundation(No. 06104396), Research Team Project in Guangdong Province Natural Science Foundation(No. 20023001).

\section{References}

1. Jain A, Karadag A, Fohr B, et al. Three SIBINGs enhance factor H's cofactor activity enabling MCP-like cellular evasion of complement-mediated attack. J Biol Chem, 2002, 277: 13700-13706. doi:10.1074/jbc.M110757200

2. Wang J, Dong Y, Zhang H B, et al. Clone of human bone sialoprotein gene and its expression in Pichia pastoris. Chinese Journal of Biochemistry and Molecular Biology, 2004, 20 (3): 325-329.

3. Li F, Xian R Q, Xing J ZH, et al. Pharmaceutical and immunological evaluation of a single-dose hepatitis B vaccine using PLGA microspheres. Journal of Controlled Release, 2006, 112: 35-42. doi:10.1016/j.jconrel.2006.01.0 $\underline{12}$

4. Lu B, Wu W. Central composite design for the optimization of dexamethasone acetate polylactide microspheres technique. Pharmacy, 1999, 34(5): 387-391.

5. Luo S, Takano M, Asakawa T, et al. Measurement of low level membrane proteins using bicinchoninic acid: modified procedures to eliminate interfering substances. Fukuoka Igaku Zasshi, 2002, 93(11): 236-246. 
6. He J T, Su H B, Li G P, et al. Stabilization and encapsulation of a staphylokinase variant (K35R) into poly(lacticco-glycolic acid) microspheres. International Journal of Pharmaceutics, 2006, 309: 101-108. doi:10.1016/j.ijphar m.2005.11.036

7. Liu L, Ge Y, Gao J Y, et al. The interaction between proteins and polymers in PLGA microsphere. East China University of Technology, 2003, 1 (29): 248-251.

Received 15 June, 2010; accepted 30 June, 2010; published online 1 July, 2010.

Copyright: (C) 2010 X. Liao et al. This is an open access article distributed under the terms of the Creative Commons Attribution License, which permits unrestricted use, distribution, and reproduction in any medium, provided the original author and source are credited. 